\title{
Food Pyramid of the Swiss Society for Nutrition
}

\author{
Paul Walter Esther Infanger Pascale Mühlemann
}

Swiss Society for Nutrition, Bern, Switzerland

\section{Key Words}

Food-based nutrition guidelines - Swiss food pyramid • Healthy lifestyle

\begin{abstract}
The Swiss Society for Nutrition issued its Food Pyramid in 2005. It was updated according to the latest scientific evidence and is in principal agreement with food-based guidelines of other countries. It has also been officially endorsed by the Swiss government. The food pyramid stands for a balanced diet that guarantees the body a sufficient supply of energy, essential nutrients and protective substances. Food from the lower levels of the pyramid should be eaten in larger quantities, and those from the higher levels in smaller quantities. The six levels from top down represent the following food groups: sweets, salty snacks and sweetened or alcoholic drinks; oils, fats and nuts; milk, dairy products, meat, fish and eggs; whole grain products and pulses, other cereals and potatoes; fruit and vegetables; beverages. A basic principle to be communicated by the food pyramid is that there are no good or bad foods but that the relative amounts to be consumed play a key role for our health. The key message is to eat a diet that is as varied as possible and which considers foods of each pyramid level in the right amounts. The recommendations do not need to be followed every day, but should be observed on a long-term basis, e.g. a
\end{abstract}

whole week. Liquid intake is an exception; liquids should be consumed on a daily basis. It is also very important to keep a healthy body weight by daily exercise as indicated by the icons on the side of the Swiss Food Pyramid.

Copyright $\odot 2007$ S. Karger AG, Basel

\section{Introduction}

A special working group of the Swiss Society for Nutrition started in 2004 with the updating of the original food pyramid issued in 1998 and results from recent literature were integrated. This paper will not review the whole literature but refers to some of the more recent pertinent results. Most important were several WHO reports, especially the Global strategy on diet, physical activity and health of the 57th World Health Assembly (WHA 57.17) and its article 22 .

For diet, recommendations for populations and individuals should include the following:

- Achieve energy balance and a healthy weight

- Limit energy intake from total fats and shift fat consumption away from saturated fats to unsaturated fats and towards the elimination of trans-fatty acids

- Increase consumption of fruits and vegetables, and legumes, whole grains and nuts

- Limit intake of free sugars

\section{KARGER}

Fax +4161306 1234

E-Mail karger@karger.ch

www.karger.com
(C) 2007 S. Karger AG, Basel

0250-6807/07/0518-0015\$23.50/0

Accessible online at:

www.karger.com/anm
Paul Walter

Schweizerische Gesellschaft für Ernährung (SGE)

Effingerstrasse 2, Postfach 8333

CH-3001 Bern (Switzerland)

Tel. +41 6140302 83, Fax +41 6140302 82,E-Mail paul.walter@unibas.ch 
Table 1. Targets for the Swiss food pyramid

\begin{tabular}{|c|c|}
\hline Nutrient, food components & Targets (per day) \\
\hline Energy & 7.4-10.6 MJ; 1,800-2,500 kcal \\
\hline Carbohydrates & about $50 \%$ of total energy \\
\hline Dietary fibre & about $30 \mathrm{~g}$ \\
\hline Saccharose & moderate, about $10 \%$ of total energy \\
\hline Protein & $10-20 \%$ of total energy \\
\hline Fat & about $30 \%$ of total energy \\
\hline Long-chain saturated fatty acids & $<10 \%$ of total energy \\
\hline Monounsaturated fatty acids & about $10 \%$ of total energy \\
\hline Polyunsaturated fatty acids & about $7 \%$ of total energy \\
\hline Relation of linoleic acid to $\alpha$-linolenic acid & $5: 1$ \\
\hline Cholesterol & about $300 \mathrm{mg}$ \\
\hline Vitamins & $100 \%$ DACH reference values for 19 - to 65 -year-old people \\
\hline Minerals and trace elements & $100 \%$ DACH reference values for 19 - to 65 -year-old people \\
\hline Salt $(\mathrm{NaCl})$ & about $6 \mathrm{~g}$ \\
\hline Water from beverages and solid foods & $\begin{array}{l}250-270 \mathrm{ml} / \mathrm{MJ} \text { or } 1.0-1.1 \mathrm{ml} / \mathrm{kcal} \text { (incl. water derived from } \\
\text { oxidations) }\end{array}$ \\
\hline
\end{tabular}

- Limit salt (sodium) consumption from all sources and ensure that salt is iodized.

The aim of the Swiss Society for Nutrition was to present easily understandable recommendations for healthy, tasty eating and drinking for adults. Another goal was to find a consensus for a food pyramid that was accepted and endorsed by the Swiss government as well as by major Swiss organizations involved in nutritional issues including major food retailers and food industries.

For the energy as well as the macro- and micronutrient requirements, the Reference Values for Nutrition Intake DACH 2002 [1] were used. The target population for the recommendations of the Swiss Food Pyramid are healthy adults aged 19-65 with a low physical activity profile (PAL 1.4: sedentary activities, with little or no strenuous leisure activity). The average nutritive targets to be fulfilled are summarized in table 1.

\section{Official Document of the Swiss Food Pyramid 2005 [2]}

\section{Recommendations for Healthy, Tasty Eating and Drinking for Adults}

Our eating and drinking patterns are influenced by a number of different factors such as individual needs and desires, our everyday health and social environment, current food availability, advertising, etc. The following recommendations are designed for healthy adults. Other age groups and population categories (e.g. children, pregnant women, athletes, vegetarians, etc.) have specific requirements which cannot all be illustrated in the same pyramid (fig. 1).

This food pyramid shows a balanced, mixed diet that guarantees the body a sufficient supply of energy, essential nutrients and protective substances, making a major contribution to our well-being. Food from the lower levels of the pyramid should be eaten in larger quantities, and those from the higher levels in smaller quantities. All food items are allowed. The key is to eat a diet that is as varied as possible and which considers each pyramid level. This diet should be seasonal and made up of foodstuffs that have been processed and prepared with care.

A healthy diet should of course be a source of pleasure and enjoyment, which is best achieved by eating in company. The recommendations do not need to be followed every day, but should be observed on a long-term basis, e.g. a whole week. Liquid intake is an exception, as these recommendations should be followed daily.

However, our health is not merely dependent on our eating and drinking habits. To maintain a healthy body weight, it is particularly important to do at least half an hour of exercise each day (in the open air if possible). Refraining from smoking and adopting a healthy attitude towards stressful situations and/or utilising specific, conscious relaxation techniques also contribute to a healthy lifestyle. 


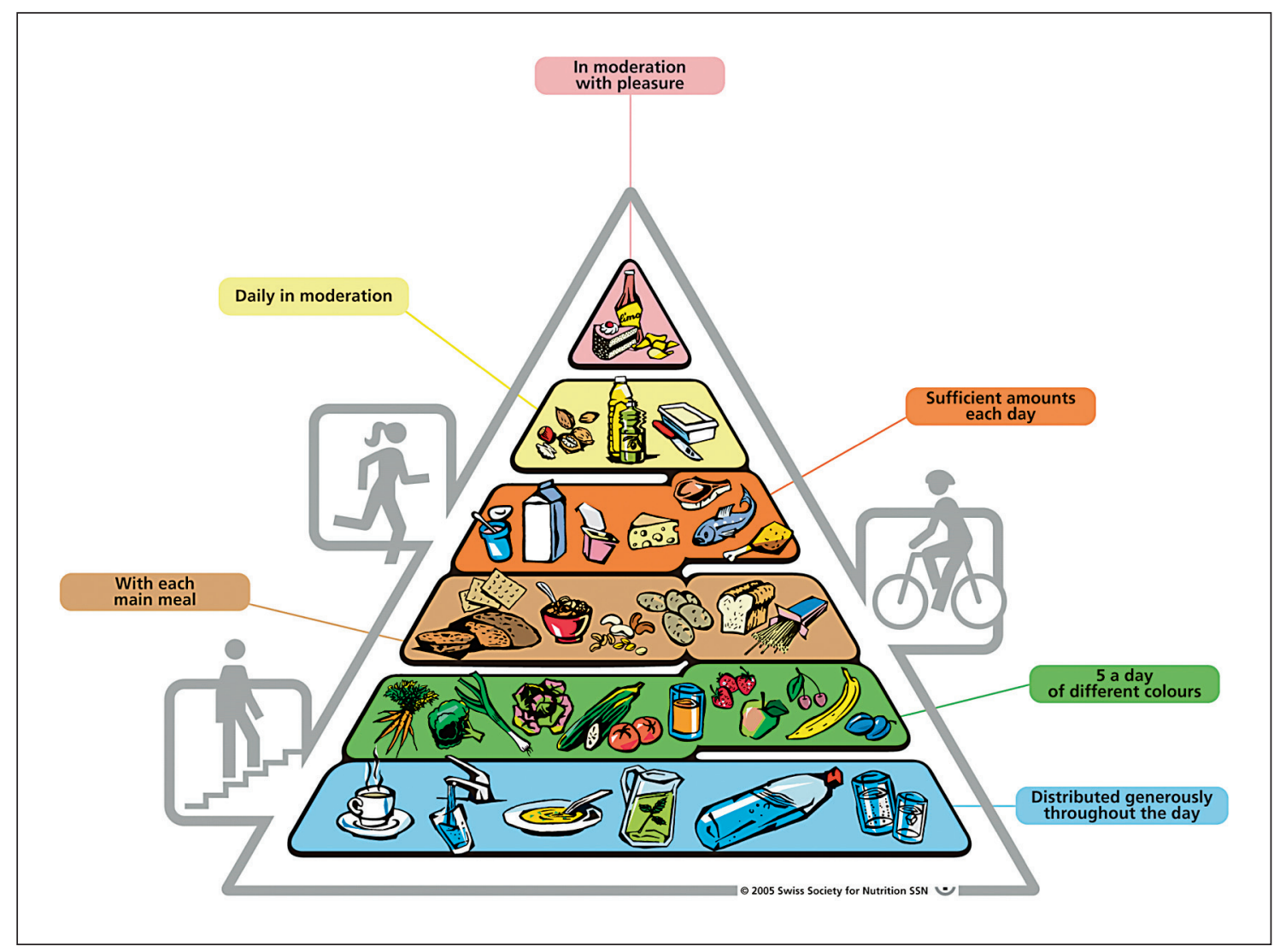

Fig. 1. Food pyramid: recommendations for healthy, tasty eating and drinking for adults.

Detailed Recommendations for the Different Levels of the Swiss Food Pyramid from Bottom to Top

Beverages - distributed generously throughout the day:

Drink 1-2 litres of liquid a day, preferably in the form of non-sugared drinks, e.g. tap/mineral water or fruit/ herb teas.

Caffeine-rich beverages (coffee, black/green tea) should be drunk in moderation only.

Fruit and vegetables -5 a day of different colours:

Eat 3 portions of vegetables a day, at least one of which should be raw ( 1 portion $=$ at least $120 \mathrm{~g}$ of vegetables, e.g. salad, soup or as a side-dish).

Eat 2 portions of fruit a day $(1$ portion $=$ at least $120 \mathrm{~g}=1$ 'handful').

One daily portion of fruit or vegetables can be replaced by $200 \mathrm{ml}$ of non-sugared fruit or vegetable juice.
Whole grain products and pulses, other cereals and potatoes - with each main meal:

Each main meal should be served with 1 starch-rich side-dish (i.e. 3 portions a day, 1 portion $=75-125 \mathrm{~g}$ of bread or 60-100 g of pulses [raw weight] for instance lentils/chick peas or 180-300 $\mathrm{g}$ of potatoes or 45-75 g of pasta/rice/flakes/corn/other grains [raw weight]), including at least two portions of whole grain products.

Milk, dairy products, meat, fish and eggs - sufficient amounts each day:

Each day, alternate between 1 portion of meat, fish, eggs, cheese or other sources of protein, e.g. tofu (1 portion $=100-120 \mathrm{~g}$ of meat/fish [fresh weight] or 2-3 eggs or $200 \mathrm{~g}$ of fresh/cottage cheese or $60 \mathrm{~g}$ of hard cheese or $100-120 \mathrm{~g}$ of tofu).

In addition, consume 3 portions of milk or dairy products a day, preferably reduced fat varieties $(1$ portion $=$ $200 \mathrm{ml}$ of milk or 150-180 g of yoghurt or $200 \mathrm{~g}$ of fresh/ cottage cheese or 30-60 g of cheese).

Ann Nutr Metab 2007;51(suppl 2):15-20 
Fig. 2. Order of food groups.

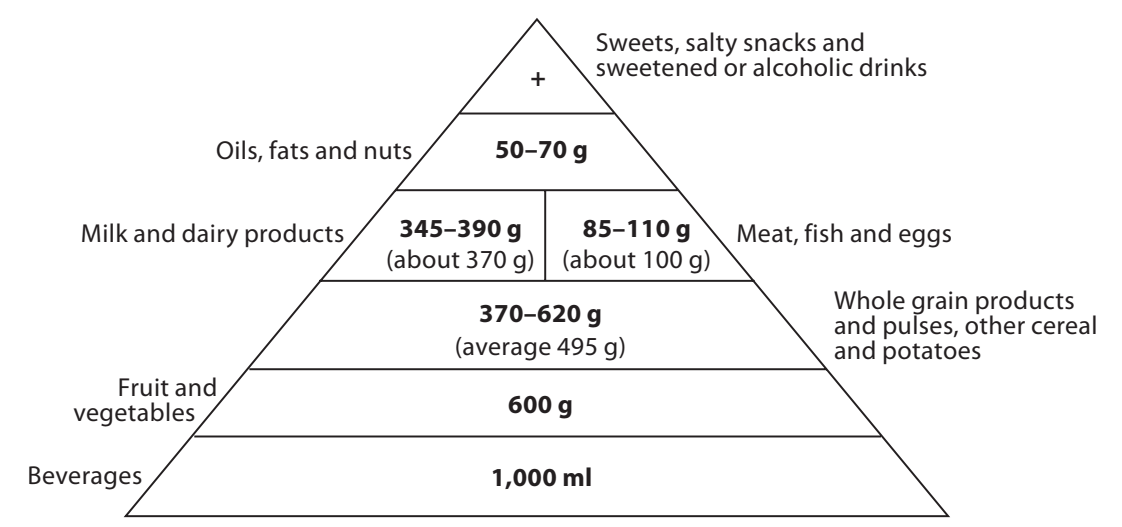

Oils, fats and nuts - daily in moderation:

2-3 teaspoons (10-15 g) a day of high-quality plantbased oils such as rapeseed oil or olive oil in cold dishes (e.g. salad sauces).

2-3 teaspoons (10-15 g) a day of plant-based oils for cooking (frying, braising): olive oil is recommended for example.

Use 2 teaspoons ( $10 \mathrm{~g})$ a day of butter or margarine made from high-quality oils to spread on bread as required.

A daily serving of 1 portion of nuts is recommended (1 portion $=20-30 \mathrm{~g}$ of almonds, walnuts or hazelnuts, etc.).

Sweets, salty snacks and sweetened or alcoholic

drinks - in moderation with pleasure:

Consume sweets, salty snacks and sweetened drinks (e.g. soft drinks, ice tea, energy drinks) in moderation.

When consuming alcoholic beverages, do so in moderation and with a meal.

Use salt with added iodine and fluoride, but only in limited quantities.

\section{Special Considerations}

\section{Order of Food Groups within the Pyramid}

The order of the various levels of the pyramid is given by the relative amounts of the foods to be consumed. From bottom up the largest group are the beverages followed by fruit and vegetables. There is a relatively small difference of the latter group to the next one containing the main sources of carbohydrates. In special cases this may individually result in a different order of these two groups. The next level contains milk and dairy products on the one hand and other protein containing foods on the other hand (such as meat, fish, etc.). Finally there is the newly introduced level for oils, fats and nuts, and on the top of the pyramid are the 'extras' to be consumed in small amounts (sweets, salty snacks, etc.) (fig. 2).

\section{Do These Recommendations Provide the}

Recommended Amounts of Nutrients?

No exact calculation can be made, since a variety of different foods can be chosen on each level of the pyramid per day (table 2). Therefore the calculations were based on a theoretical 7-day food protocol with daily changes in the choices at each level. The calculations were performed with a special software (Prodi 5 from Nutriscience). Some of the results are shown in tables 3 and 4 . The macronutrient distribution, shown as percentage of total energy, as well as the distribution of the various fatty acids correspond to the recommendations (see table 1). No calculation on the ratio of $\omega-6$ to $\omega-3$ fatty acids could be performed. However, if the recommendation for the intake of fat and oils (especially rapeseed oil) is followed, this quotient will approach the recommended value of 5:1. Of the critical minerals measured, calcium as well as magnesium reached the recommended daily amounts, whereas zinc, iron and iodine just about reached the recommended levels. Of the water-soluble vitamins, the critical ones $B_{1}, B_{2}, B_{12}$, folic acid as well as vitamin $C$ all reached the recommended levels. Somewhat surprisingly, the calculated intake of vitamin A reached only $50 \%$ and for vitamin $\mathrm{D}_{3}$ only $20 \%$ of the recommended amounts. Due to the high availability of $\beta$-carotene in 
Table 2. Calculated intake per day

$3 \times 120 \mathrm{~g}$ of vegetables and $2 \times 120 \mathrm{~g}$ of fruit

$3 \times$ starch-rich side-dish with $30-50 \mathrm{~g}$ of carbohydrates each

$3 \times$ milk or dairy products with $240 \mathrm{mg}$ of calcium each

(all but cheese with reduced fat content)

$1 \times$ meat, fish, cheese, eggs, tofu or Quorn ${ }^{\mathrm{TM}}$ with $20 \mathrm{~g}$ of protein each

$30-40 \mathrm{~g} \mathrm{oil} / \mathrm{fat}$

20-30 g mixture of nuts

max. $45-60 \mathrm{~g}$ of sugar (= $10 \%$ of energy intake)

max. 1-2 dl of wine (approx. 10-20 g of alcohol)

Table 3. Macronutrients

\begin{tabular}{lcl}
\hline Energy & $\begin{array}{l}9 \mathrm{MJ} \\
(2,150 \mathrm{kcal})\end{array}$ & $\begin{array}{l}\text { \% of total } \\
\text { energy }\end{array}$ \\
\hline Protein & $87 \mathrm{~g}$ & 16 \\
Carbohydrates & $242 \mathrm{~g}$ & 45 \\
Fat & $82 \mathrm{~g}$ & 34 \\
Dietary fibre & $34 \mathrm{~g}$ & \\
Cholesterol & $207 \mathrm{mg}$ & \\
Alcohol & $14.4 \mathrm{~g}$ & 5 \\
Beverages & $1.2 \mathrm{l}$ & \\
\hline
\end{tabular}

fruit and vegetables, enough vitamin A can be produced through cleavage of the $\beta$-carotene in the gut of the consumer. Similarly, the extra vitamin $\mathrm{D}_{3}$ synthesis in the skin will take care of the necessary vitamin $\mathrm{D}_{3}$ supply which is why at least half an hour of exercise per day is recommended in the open air if possible. In conclusion, it can be said that all the critical nutrients are supplied in sufficient amounts by the recommended diet of the Swiss Food Pyramid to meet the daily requirements by $\mathrm{DACH}$ [1].

\section{Special Emphasis}

The main problem for full acceptance and application of the food-based guidelines by the population is the recommended high daily consumption of vegetables and fruit which are not always easily available and may result in an increase of the family budget for food. Therefore, the simpler the message the higher the chance that fruit and vegetable consumption will increase. In our experience, the food pyramid has retained its role as an excellent way to communicate the basic messages for a healthy diet in a short time.
Table 4. Fatty acids

\begin{tabular}{llcc}
\hline & $\begin{array}{l}\text { Amount } \\
\mathrm{g}\end{array}$ & $\begin{array}{l}\text { \% of total } \\
\text { fatty acids }\end{array}$ & $\begin{array}{l}\text { \% of total } \\
\text { energy }\end{array}$ \\
\hline Fat & 82 & - & 34 \\
Saturated fatty acids & 26 & 35 & 12 \\
Monounsaturated fatty acids & 33 & 46 & 16 \\
Polyunsaturated fatty acids & 14 & 19 & 6 \\
Total fatty acids & 73 & 100 & - \\
\hline
\end{tabular}

Research of the last 10 years has fully confirmed the large beneficial effect of the 5-a-day concept of fruit and vegetable on the reduction of cardiovascular disease and stroke $[3,4]$ by 20 and $30 \%$, respectively. The higher consumption of whole grain also results in a reduction of the risks for the two diseases mentioned above [5]. Even though the mechanisms for these effects are not fully elaborated, it is evident that many biologically active compounds occurring in fruit and vegetable as well as in whole grain are at least in part responsible for these effects [6]. The recommendation for a daily consumption of nuts is new; nuts have been shown to have several health effects mainly due to their healthy fat composition $[7,8]$.

In view of the actual obesity pandemic, the proper control of the energy balance and the correct application of the food-based guidelines by the general population can be expected to result in a strong reduction of the health costs for the treatment of the occurring diseases like diabetes and the metabolic syndrome. In Switzerland alone, these extra costs are now estimated to amount to CHF 2.5 billion per year [9]. As in many other countries it is unfortunately politically very difficult to attribute the necessary funds to implement the food-based guidelines on a large scale. The methods are available, but the finances for the implementation are at present largely insufficient.

\section{Acknowledgements}

In addition to the authors, the following individuals were members of the special working group of the Swiss Society for Nutrition: Monika Eichholzer, Priska Gnägi-Schwarz, Josef Laimbacher, Kathrin Reinli, and Paolo Colombani. 


\section{References}

1 German Nutrition Society, Austrian Nutrition Society, Swiss Society for Nutrition Research, Swiss Nutrition Association: Reference Values for Nutrient Intake, ed 1. Frankfurt, Umschau Braus Publisher GmbH, 2002.

2 Swiss Food Pyramid http://www.sge-ssn.ch/ science/scientific_publications/ssn_publications/food_pyramid/english/food_pyramid_65_engl.pdf

3 Dauchet L, Amouyel P, Hercberg S, Dallongeville J: Fruit and vegetable consumption and risk of coronary heart disease: a metaanalysis of cohort studies. J Nutr 2006;136: 2588-2593.
4 Dauchet L, Amouyel P, Dallongeville J: Fruit and vegetable consumption and risk of stroke: a meta-analysis of cohort studies. Neurology 2005;65:1193-1197. Summary for patients in: Neurology 2005;65:E17-E18.

5 Steffen LM, Jacobs DR Jr, Stevens J, Shahar E, Carithers T, Folsom AR: Associations of whole-grain, refined-grain, and fruit and vegetable consumption with risks of allcause mortality and incident coronary artery disease and ischemic stroke: The Atherosclerosis Risk in Communities (ARIC) Study. Am J Clin Nutr 2003;78:383-390.

6 Kris-Etherton PM, Hecker KD, Bonanome A, Coval SM, Binkoski AE, Hilpert KF, Griel $\mathrm{AE}$, Etherton TD: Bioactive compounds in foods: their role in the prevention of cardiovascular disease and cancer. Am J Med 2002; 113(suppl 9B):71S-88S.
7 Kris-Etherton PM, Zhao G, Binkoski AE, Coval SM, Etherton TD: The effects of nuts on coronary heart disease risk. Nutr Rev 2001;59:103-111.

8 Gebauer SK, Psota TL, Harris WS, KrisEtherton PM: n-3 fatty acid dietary recommendations and food sources to achieve essentiality and cardiovascular benefits. Am J Clin Nutr 2006;83(6 suppl):1526S-1535S.

9 Schneider H, Schmid A: Die Kosten der Adipositas in der Schweiz. Schlussbericht für das Bundesamt für Gesundheit (BAG). Bern, BAG, 2004. www.bag.admin.ch 